Vol. XXI No $3 \quad 2015$

\title{
GEOSPATIAL DATA RELIABILITY, THEIR USE IN CRISIS SITUATIONS
}

\author{
Š́ára HOŠKOVÁ-MAYEROVÁ \\ University of Defence, Brno, Czech Republic \\ sarka.mayerova@unob.cz
}

\begin{abstract}
Spatial data are used not only for basic orientation in space but also as data for solving tasks connected with actual decisions, e.g. geographic impact on combat and non-combat army activities in given environments, predictions of landscape damage under extreme meteorological conditions or emergencies, in cases of military threats to the state, etc. in many tasks the source data are combined and based on mathematically or procedurally described processes, new data are created. Currently, computer equipment, geographic information systems (GIS), remote sensing, computer cartography, etc. in the hands of professionals, along with expert systems, can help much faster, more reliable and more efficient leadership of crisis management. When employing spatial data and information in decision-making processes, complex knowledge of their values is the prerequisite for assessing the credibility and accuracy of decisions made. By implementing the methods of value analysis and mathematical modeling it is possible to create an assessment system of spatial data complex usability. By comparing costs necessary for different variants of enhancement or for adjustment of database quality it is possible to optimize both the total usability and the costs put in securing the required data quality. Paper describes one possible way of creation of cost map.
\end{abstract}

Keywords: spatial data, quality assessment, crisis situation, geospatial data reliability, mathematical model

\section{Introduction}

Protection of the population cannot be under-estimated; emergences, natural disasters, industrial accident, landslides, floods, fires, etc. can never be predicted and always come unexpectedly.

\section{Emergencies always select the time when} they attack!

It is evident that a natural disaster is the consequence of a natural hazard (e.g. volcanic eruption, earthquake, landslide) which moves from potential into an active phase, and as a result affects human activities. Human vulnerability, exacerbated by the lack of planning or lack of appropriate emergency management, leads to financial, structural, and human losses. The resulting loss depends on the capacity of the population to support or resist the disaster, their resilience. This understanding is concentrated in the formulation: "disasters occur when hazards meet vulnerability". A natural hazard will hence never result in a natural disaster in areas without vulnerability, e.g. strong earthquakes in uninhabited areas. This emergency situation can efficiently be prevented if the staff is professional, well trained and sufficiently flexible to respond. Emergency management is highly dependent on economic and social conditions relevant to the emergency or disaster. Emergency or disaster management involves preparing, supporting and recovering society when natural or mancaused disasters happen. 
It can be characterized as a process in the course of which individuals and communities try to manage hazards in order to avoid the impact of disasters resulting from hazards. Emergency management is one of a number of terms which have replaced the term Civil Defense whose primary focus consisted in protecting civilians from a military attack. See e.g. [2], [8]:

"...effective emergency management requires both improvisation and preparedness. Without improvisation, emergency management loses flexibility in the fact of changing conditions. Without preparedness, emergency management loses clarity and efficiency in meeting essential disaster-related demands". [14]

\section{Quality and reliability of spatial data concept}

Basic localization database for command and control is created by the Geographic Service of the Army of the Czech Republic. In a number of tasks the source data are combined and based on mathematically or procedurally described processes, new data are created. The produced data are intended for consumption, which means they are to be used in concrete spatial analyses, planning and management. From the user's perspective, systems for data evaluation are also highly important, particularly for their feature of utility value assessment [10]. Technical functionality can be assessed generally without knowing the particular task, methodology or spatial information use. Other quality components, particularly reliability, must be assessed with relation to the given implementation in a given process. Document [13] lists a definition of characteristics and quality parameters with regard to information on cross-country communication network which draws on ISO 19113 but is adapted to given purposes. According to [13], it is possible to assess the quality of spatial data and information according to the criteria $k_{i, j}$ (for more details see Table 1 in [11]).

\section{Functionality of database of spatial data}

With regard to the application of value analysis theory, we may assess the utility value as a degree of digital spatial data database functionality $\left({ }^{\circ} \mathrm{F}\right)$ which can be expressed by the following aggregate function:

$$
{ }^{\circ} F=p_{1} k_{1}+p_{2} k_{2}
$$

where variable $k_{i}$ expresses the main quality criteria and $p_{i}$ represents the weights of individual criteria. As a rule, the main criteria are expressed as a set of partial criteria which also have their own weights (for more see [2] or [10]).

When assessing the utility of used part of a database, the ideal level of quality must be defined at first. This ideal level then works as a comparative etalon for expressing the level of meeting the individual criteria in the given assessed part of spatial database. Upon implementing the comparative etalon, the level of compliance the individual criteria may be assessed and consequently also the total utility value or the degree of user function $F$.

The level of meeting individual criteria can be generally expressed by the following formula:

$u_{s}=k_{s} / k_{s}^{*}$,

$k_{s}$ represents the value of compliance the $s$ 'th partial criterion, $k_{s}{ }^{*}$ is the degree of compliance the $s$ 'th partial criterion or criteria of its sub-group under the comparative etalon. The total individual used value of database is given by aggregate function:

$U^{x}={ }^{\circ} F^{x}=p_{1} u_{1}^{x}+p_{2} u_{2}^{x}$.

\subsection{Change in functionality of spatial database}

Owing to the fact that spatial databases can never be ideal, it is recommendable to assess the impact of the aggregate function's individual components on changes in the database. In this case we may 
use derivatives of the $U^{x}\left({ }^{\circ} F\right)$ function according to individual variables which express the levels of meeting the given criteria. Generally, the impact of changes in compliance the main $i^{\text {th }}$ criterion can be expressed in the following way:

$$
d^{\circ} F=d U / d u_{i} .
$$

However, the degrees of compliance the main criteria are represented by functions of more variables. In order to express the value $d u_{i}$, it is possible to employ two methods depending on the required information structure. If the impact of individual variables on the total individual utility value should be assessed upon an assumption that all other variables are constant, derivations of function $U$ must be expressed in the following way:

$$
d^{\circ} F=\frac{d U}{d u_{i}} \frac{d u_{i}}{d x}
$$

where $x$ is one of the given variables.

In practice, a situation may arise that a number of factors may be changed at a time, e.g. the technical quality of database is changed in all its parameters - used methods of secondary data inference are improved, localization and attribute accuracy and data complexity are enhanced and simultaneously data are placed in a geodatabase accessible to authorized users where all topological, thematic and temporal relations are well treated. In this case it is recommended to express the value of $d u_{i}$ as the total differential of all the variables. See [9, 11].

Through mathematical modelling it is then possible to solve tasks of the following types:

- how a change in a given partial parameter or several parameters of a database is reflected in its total usability;

- hich parameters need to be changed to achieve the required product functionality;

- which parameters may be "degraded" owing to the fact that the product's functionality is unnecessarily high?

\section{Model situation---example}

Above described procedure was used in the task "Finding the most beneficial route". The main aim of this task was to judge several possible calculated paths for the military vehicle Tatra 815 , for more details see [12]. These paths were calculated in the „cost map (CM)“" based on the patency parameters for this type of vehicle. In the experiment two versions of cost map were used. Map versions were created based on usable property changes of the database. Particularly, in this case we mean changes in topographic database, soil type database and digital elevation model. In our case the $\mathrm{CM}$ was created based on the parameters which evaluated influence of geographical factors for the cross-country movement of vehicles, published in [6]. Values of final pixels in $\mathrm{CM}$ were given by aggregate function for calculation of deceleration coefficients (formula 3.2 in [6]). As mentioned before two versions of database were used - before and after update. The option before the update has only a limited number of filled thematic attribute concerning reliability. Only 5 percent of data were known. After update the thematic attribute were filled in $99 \%$. In the first case the functionality of database was 0,8830 , in second case 0,9132 .

The ideal state of functional level is 1,0068 (i.e. performance standard). The positive change of database functionality cause higher costs necessary to ensure the data, e.g. the cost and time necessary to fill in the declared attributes. In the decision making process it raise an important question: Were the resources spent efficiently with respect to the increase reliability of the suggested path?

Three routes were calculated in the environs of Brno with area of $400 \mathrm{~km}^{2}$. Only the impact of terrain steps like embankments, excavations etc. was evaluated for simplification. The rest of other objects and phenomena were constant. No impact of terrain steps was evaluated in the first case. 
This route was $30.295 \mathrm{~km}$ long and its duration was 24 minutes. In the second case, when only passable steps were considered, the suggested route was 29.414 $\mathrm{km}$, but the duration was 26 minutes. The third route was calculated after database updating. Its length was $31.339 \mathrm{~km}$ and duration was 25 minutes. Also in this case only passable steps were considered (See Figure 1).

Theoretically, all routes can be used. If the first case is used, the route is more risky, so the commander assumes the risk that the vehicle cannot be able to overcome the obstacle on the selected road. In the second and third cases the probability of correct decision is high, so the vehicle should not get into trouble with overtaking of obstacles.

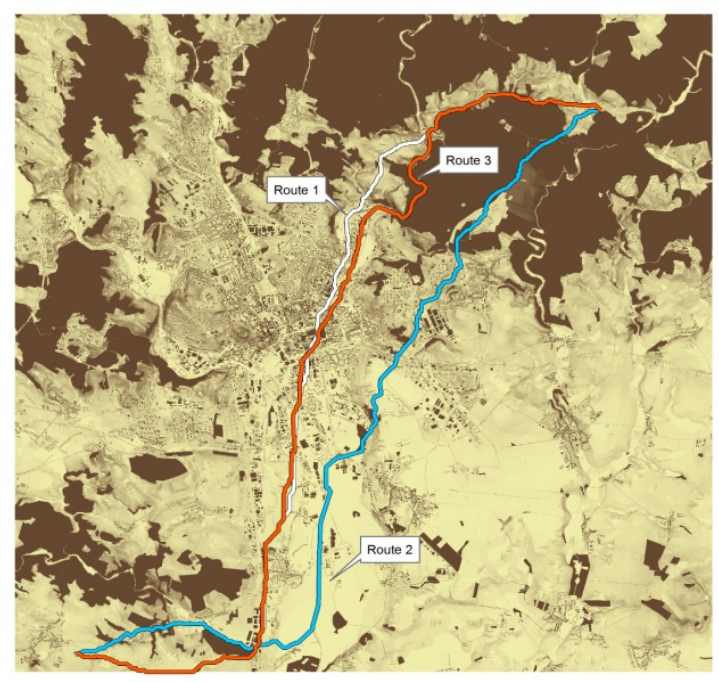

Figure 1. The most suitable route for the vehicle (search results)

This simple example was chosen only for comparing how the database functionally and reliability of decision making process matched together. In the complex evaluation is necessary to evaluate the impact of all terrain features in the area on cross country mobility.

\section{Conclusions}

There is much diversity in civil protection activities and organizations in the world and some common elements have evolved. When entering the $21^{\text {st }}$ century, civil protection has finally become accepted as a major governmental responsibility practically in every country in the world. Two decades ago, United Nations survey found dozens of countries with no formal national disaster planning and no explicit civil protection organization at that level.

Planning for disasters is not too high on the attention agenda of citizens at large. Most of population in modern societies can see civil protection as both an acceptable and accepted responsibility of the government; this percentage crosses various political ideologies, regardless left or right oriented.

Spatial data are used not only for basic orientation in space but also as data for solving tasks connected with actual decisions, e.g. geographic impact on combat and non-combat army activities in given environments, predictions of landscape damage under extreme meteorological conditions or emergencies, in cases of military threats to the state, etc. in many tasks the source data are combined and based on mathematically or procedurally described processes, new data are created.

When employing spatial data and information in decision-making processes, complex knowledge of their values is the prerequisite for assessing the credibility and accuracy of decisions made. By implementing the methods of value analysis and mathematical modeling it is possible to create an assessment system of spatial data complex usability. Based on input characteristics of the used spatial data and databases, quality characteristics and their changes can be calculated with the help of analytical methods. By comparing costs necessary for different variants of enhancement or for adjustment of database quality it is possible to optimize both the total usability and the costs put in securing the required data quality. The proposed solution aims to streamline the activities associated with the use of inhomogeneous data and information systems, command and control so that operational components should be available not only its own database, as well as relevant documentation 
about the quality and reliability of data used. Based on this information they can in their decisions to work with those documents and where appropriate their decisions correct.

\section{Acknowledgements}

The work presented in this paper was supported within the project for Support for Mathematical and Physical Research supported by the Ministry of Defence the Czech Republic.

\section{References}

[1] D'Amico, P., Di Martino, F., and Sessa, S., A GIS as a Decision Support System for Planning Sustainabel Mobility in a Case-Study. In A. Ventre, A. Maturo, S. HoskovaMayerova, \& J. Kacprzyk (Eds.), Multicriteria and Multiagend Decision Making with Applications to Economics and Social Sciences (Studies in Fuzziness and Soft Computing ed., pp. 115-128). Berlin Heidelberg, Germany: Springer Verlag. 2013.

[2] Š́rka Hošková-Mayerová, Leadership - training of military specialists in particular disciplines focused on mathematical modelling, Procedia - Social and Behavioral Sciences, 2015, CY-ICER, Cyprus 2015, in print.

[3] Kovařík, V. Use of spatial modelling to select the helicopter landing sites. Advances in Military Technology, 89(1), pp 10., 2014.

[4] Kreps, G.: Organizing for emergency management, In Emergency Management: Principles and Practice for Local Government. Washington, D.C.: International City Management Association, pp. 30-54, 1991.

[5] MoD-GeoS. (2010). Catalogue of the Topographic Objects DMU25 (7.3 ed.). Dobruska: Ministry of Defence of the Czech Republic, Geographic Service.

[6] Rybansky, M., Cross-Country Movement, The Imapct and Evaluation of Geographic Factors (First ed.). Brno, Czech Republic: Akademické nakladatelství CERM, s.r.o. Brno. 2009.

[7] Rybanský, M., and Vala, M. Analysis of relief impact on transport during crisis situations. Moravian Geographical Reports, 17(3), pp. 19-26, 2009.

[8] Stepanek, L., Urban, R. and Urban, R., A new operational risk assessment technique: the CASTL method, Journal of Operational Risk, 8(3), pp. 101-117, 2013.

[9] Talhofer, V., Hoskova-Mayerova, S., and Hofmann, A., Improvement of digital geographic data quality. International Journal of Production Research, 50(17), pp. 48464859, 2012.

[10]Talhofer, V., Digital Geographic Data: Potential Evaluation. AGILE 2004, 7th Conference on Geographic Information Science, Conference proceedings, pp. 675-686, Heraclion, Crete, Greece: AGILE. 2004.

[11]Talhofer, V., Hošková, Š., Hofmann, A., Kratochvíl, V., Reliability of finding the most beneficial route, Science and Military,7(1), pp. 36-39, 2012.

[12]Tatra, a.s., Tatra is the solution. Získáno 17. 5 2010, z TATRA: $\mathrm{http}$ //partners.tatra.cz/exter_pr/vp/new/typovy_listprospekt.asp?kod=341\&jazyk=CZ

[13] Vghmúr. (2010). Catalogue of topographic objects. Version 6 (2006). Dobruška: Military geographic and hydrometeorologic office. (In Czech)

[14] Kreps, G.: Organizing for emergency management, In Emergency Management: Principles and Practice for Local Government. Washington, D.C.: International City Management Association, 1991. p. 33. 